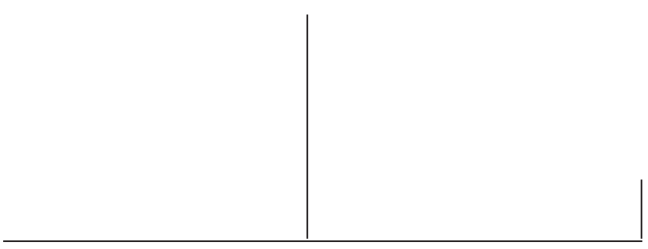

Rev. Latinoam. Psicopat. Fund., V, 3, 83-91

\title{
Frei Galvão:
} a cura sem método

Durval Mazzei Nogueira Filho

O autor, a partir da história de Frei Galvão, pergunta-se sobre o diálogo possível entre a ciência e a religião.

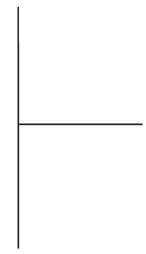

Palavras-chave: Frei Galvão, ciência, religião 


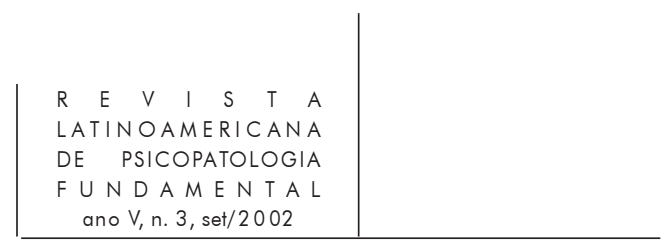

Não se sabe ao certo o ano de nascimento do Frei. 1738 ou 1739 (Surian, 1998). A cidade foi Guaratinguetá, no vale do rio Paraíba. Rio que também foi palco do encontro da imagem venerada na cidade contígua - Aparecida do Norte - onde foi construído o santuário à devoção da "Mãe Preta", Nossa Senhora Aparecida.

Quarto filho (Moura, 1993) do casamento do português Antônio Galvão de França com Isabel Leite Barros, paulista da cidade de Pindamonhagaba, e trineto do bandeirante Fernão Dias. Nasceu com o nome do pai: Antônio Galvão de França.

Em 1760 (Lima, 1998) ingressou no noviciado da Província Franciscana da Imaculada Conceição, no Convento de São Boaventura de Macacu, no Rio de Janeiro, depois de estudar no colégio dos jesuítas em Belém, Bahia. Ordenado sacerdote em 1762, adotou o próprio nome: Frei Antônio de Sant'ana Galvão. Neste ano, vem a São Paulo a pé (traço que caracterizou a sua biografia: fez por diversas vezes o trajeto de São Paulo ao Rio de Janeiro a pé) e matriculou-se no curso de Filosofia, no Convento de São Francisco. Terminou os estudos em 1768. Desempenhou neste mosteiro a função de porteiro, função importante na regulação do contato entre os religiosos e a polis ao redor, e a função de confessor de leigos e outros religiosos.

Enquanto desenvolvia suas funções no Convento de São Francisco, durante o ano de 1774, fundou e iniciou a construção do Recolhimento de Nossa Senhora da Conceição da Divina Providência, o conhecido, até os dias de hoje, Mosteiro da Luz. A construção baseouse em uma concepção arquitetônica de sua autoria. Segundo Surian (1998), "ele mesmo foi o desenhista, o arquiteto, o mestre de obras, o pedreiro, o servente, o carpinteiro". 


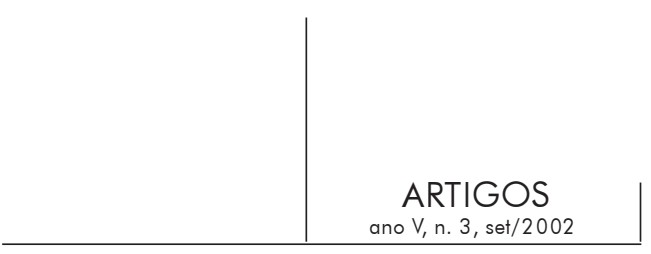

Boa parte de sua vida foi ocupada pela construção do mosteiro e as viagens a pé - missões missionárias - entre São Paulo, Rio de Janeiro e outras cidades do estado de São Paulo.

Faleceu antes de completar 84 anos, em 1822, na cidade de São Paulo. Está sepultado na capela-mor da Igreja do Mosteiro da Luz.

\section{Um comentário}

O autor deste texto não é exatamente versado na vida pessoal dos sujeitos consagrados pela santidade na iconografia católica. Não obstante, esperava uma existência mais marcada por acontecimentos espetaculares que sugerissem a imersão do sujeito na divindade, que indicassem sua condição de avatar próximo à divindade mesmo nas ações mundanas e seculares. Tal não ocorre na biografia de Frei Galvão. Trata-se de um homem perfeitamente integrado na vida da cidade.

Surian (1998) é quem relata, não sem salientar que este traço era familiar, um episódio infantil no qual o jovem Antônio teria dado como esmola uma toalha de grande valor, propriedade da família. A suplicante teria, mais tarde, voltado à sua casa para devolver o objeto e a família não aceitou a devolução, legitimando a generosidade do menino. Há de considerar que, provavelmente, o garoto não tinha a menor idéia do valor da toalha. Este episódio, na verdade, indica uma eqüitativa divisão da nobreza e da dignidade por todos os protagonistas e, menção especial - ato realmente santo - corresponde à pobre mulher que tendo recebido a prenda, devolve-a.

Algo similar se dá nos pródromos da construção do Mosteiro da Luz. Obra projetada e levada adiante por Frei Galvão - nada mais humano e perseverante, lhe foi anunciada por uma irmã, de quem era o confessor: a irmã Helena. Esta foi quem recebeu de Jesus que "mediante palavras, sinais, visões, lhe pedia a fundação de um outro mosteiro em São Paulo, para outras ovelhas que estavam fora do aprisco" (Surian, 1998). Frei Galvão, o das curas milagrosas, não acatou, de chofre, a revelação da piedosa irmã. Na verdade, levou o caso ao "bispo diocesano e este a um conselho de doutos e experimentados sacerdotes" (Ibid.). Novamente, o curioso estado de coisas no qual o futuro beato não é ele o receptor de mensagens místicas e não é um escrutínio pessoal a decisão sobre a verdade da manifestação da divindade. Pelo contrário, obedientemente, leva o ocorrido para instâncias superiores que, pela própria organização das reuniões, decide em termos mais racionais.

O traço distintivo da biografia de Frei Galvão resume-se a seu gosto pelas longas caminhadas. Pois, a referência às curas e outras manifestações de tom 


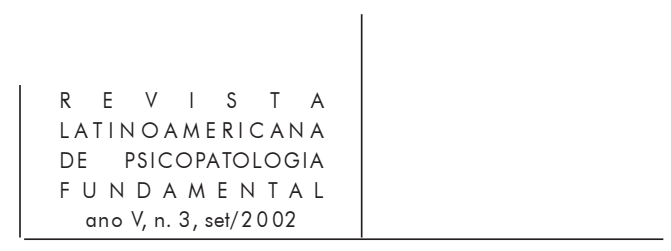

místico em momento algum foram objeto de declarações do religioso e também não foram transformadas pelo Frei em prestígio pessoal. São histórias contadas pelos outros e as tais curas ao Frei atribuídas não foram presenciadas pelo curador. Novamente, as histórias configuravam-se relatos.

\section{Os milagres atribuídos ao Frei}

Não são muitas as curas atribuídas ao Frei. Figuram aqui e ali, na trajetória de sua longa existência, alguns episódios onde os relatos as afirmam. Encontramos, na parca literatura pesquisada, dois episódios. Aquele que forjou a fama das "pílulas" do Frei Galvão é assim relatado por Surian (1998):

... assim aconteceu que vieram suplicar-lhe a cura de um rapaz que sofria violentas dores por causa de uma pedra na bexiga. O Santo homem recomendou calma, confiança, oração e, tomando um pedaço de papel, nele escreveu um louvor a Nossa Senhora Mãe de Deus ("Depois do parto, ó Virgem, permaneceste intacta. Mãe de Deus, intercede por nós", segundo Lima [1998]).

Enrolou o papel e o cortou em pedacinhos (pílulas) e os mandou tomar a modo de remédio de cura rápida e total. Este rapaz sofria de cólicas renais, segundo os relatos.

Um segundo episódio inclui os fenômenos que, segundo os contadores de histórias, marcou a existência de Frei Galvão; a ocorrência de algo similar à telepatia e à possibilidade de bilocação, a chance de estar em dois lugares ao mesmo tempo. Conta Moura (1993) que um morador de uma fazenda, a algumas léguas de São Paulo, veio procurá-lo no Convento de São Francisco para que intercedesse a favor de sua esposa. Esta caíra gravemente enferma, na véspera de um parto. Não o encontrou. Estava no Rio de Janeiro. Entretanto, ao voltar desolado para casa, escreve Moura,

... qual não foi sua surpresa ao encontrar a esposa livre de todo o perigo, e a proclamar o poder de seu grande benfeitor Frei Galvão! Contou-lhe, então, a enferma como lhe aparecera o Servo de Deus, durante a noite, muito chuvosa e, no entanto, completamente enxuto. Ouvira-a em confissão e mandando vir um copo com água, abençoou-a e deu-lho a beber, sendo isto o bastante para que se normalizasse o seu estado.

São relatos. Envolveram uma vida onde o reconhecimento como milagreiro, como santo, o acompanhava sem o concurso de qualquer forma de mistificação. Sem que fosse necessário qualquer local apropriado para onde o povo aflito afluísse, em busca do milagre. Outras histórias contam a interferência do Frei 


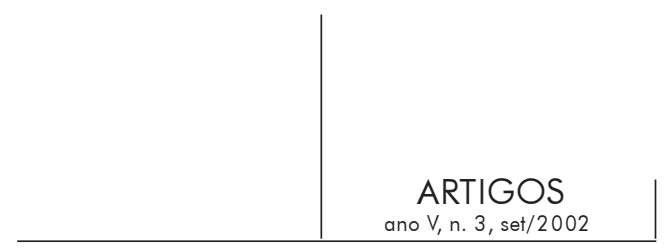

em conflitos conjugais, na reconciliação de inimigos, na presença bilocada para uma pia extrema-unção em doentes terminais.

Em complementação, a presença de Frei Galvão neste século desencantado, neste século científico, dá-se na cura, relatada como milagrosa, por um pediatra em 4 de agosto de 1995. A menina, Daniela Cristina da Silva, nascida em 1986 e moradora da cidade de São Paulo, que de uma hospitalização por complicações bronco-pulmonares evoluiu com diagnóstico de insuficiência hepática grave, insuficiência renal aguda com conseqüências tais como crises convulsivas. Permaneceu em UTI por 12 dias e recebeu alta hospitalar em 21 de junho de 1990, completamente curada. Segundo Lima (1998), texto de onde retiramos as informações sobre a patologia de Daniela, "a intervenção de Deus foi pedida pelos pais, parentes, amigos, vizinhos e religiosos do Mosteiro da Luz que, unidos numa só prece, invocaram com muita fé a intercessão de Frei Antônio de Galvão, dando à menina água e pílulas de Frei Galvão". Este foi o acontecimento reconhecido pelo Vaticano, graças ao qual o Frei foi beatificado.

\section{Outro comentário}

Salta aos olhos, como apontado no comentário sobre a biografia de Frei Galvão, o não-comprometimento do Frei com seus milagres. Não há, em sua existência, referência ao estabelecimento do Frei em um santuário especial onde ministrasse suas curas. Não há referência ao uso de objetos que representassem o catolicismo. Nem cruz, nem água benta, nem invocação de um santo mais tradicional. Apenas a referência aos pedacinhos de papel, tomados à maneira de pílulas, onde o Frei escreveu um louvor a Maria. Um ato de criatividade e de instilação de esperança, envolvido em benção e oração mais do que uma tentativa organizada e ritualística de cura.

A única referência a um comentário articulado pelo próprio religioso, encontramos em Moura (1993). A propósito da recuperação da saúde da mulher do fazendeiro, o Frei teria dito "como se deu, não sei; mas a verdade é que naquela noite lá estive". Nada mais descomprometido com a assunção pelo eu de um poder ou de um saber que lhe é revelado, que é intransmissível, e do qual é o único capaz de mobilizá-lo. E, como indicado anteriormente, não há referência em sua biografia à dedicação a práticas religiosas notavelmente meditativas, a grandiosos jejuns, a autoflagelos, a penitências sem fim com a intenção de alçar a santidade, a condição de milagroso. Tratava-se de um religioso cidadão que nada a mais fez que seus companheiros franciscanos ou qualquer outro sujeito que se dedique à formação religiosa dentro do cânone católico. O reconhecimento da condição 


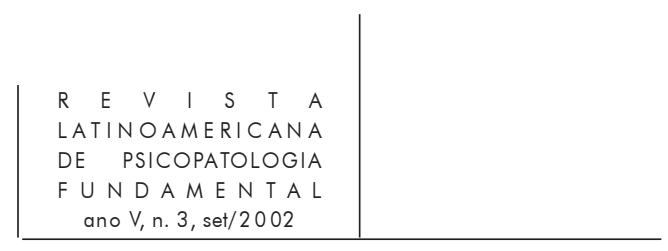

de homem especial era exclusivamente alheio. Os circunstantes, os observadores, o povo, enfim, atribuía-lhe a santidade, sem que o Frei ansiasse tal reconhecimento.

Não é a regra quando adentramos o campo das curas fora da racionalidade científica ocidental.

À guisa de comparação, recorremos à descrição que o psicanalista Sudhir Kakar faz do pir muçulmano, em seu belo estudo sobre as tradições curativas da Índia. O pir muçulmano é reconhecido pelo povo que a ele acorre como curador mas, sobretudo, reconhece-se como um homem dotado de poderes especiais. Diz Kakar (1998):

... os acontecimentos dramáticos e inusitados imediatamente depois do nascimento, a renúncia [voluntária] aos laços humanos normais como o matrimônio, uma linhagem profissional antiga e uma longa aprendizagem com um pir distinguido contribuíram à sua própria imagem (confirmada por seus clientes) como curandeiro dotado que possui poderes singulares.

Observam-se diferenças radicais entre a história do Frei brasileiro e as características biográficas e culturais do pir muçulmano. O pir representa uma tradição de curandeiros e é, propriamente, possuidor não só de uma biografia com traços especiais como de um saber particular. Segundo Kakar, os poderes do pir associam-se a um sistema muito maior de conhecimento ao qual os muçulmanos chamam ilm-i-ruhani, o conhecimento da alma.

Desta forma, obedecendo aos ditames deste conhecimento arcano, as curas são obtidas no contexto de um ritual que tem como condição

... que o feiticeiro seja puro de mente e corpo, honrado e sempre verdadeiro. Antes de começar o ritual, o feiticeiro se encerra em um compartimento, para uma semana de purificação. O compartimento é untado por uma substância vermelha e o feiticeiro estende uma esteira vermelha para orar e repete os poderosos nomes de Deus. Sua dieta é controlada estritamente e seus diversos componentes dependem se se repete os nomes terríveis ou afáveis de Alá. Depois disto, permanece recluso por 40 dias em algum lugar separado onde não pode ser molestado e realiza a invocação específica para conjurar os gênios. São 137.613 vezes e as divide em 40 partes, uma para cada dia. (Ibid.)

Alcançar "estados de consciência alterados" (Ibid.), dentro de uma contextualização claramente esotérica e mística, é o objetivo desta preparação.

Esta descrição evidencia a diferença entre as curas do beato católico e as outras práticas curativas, nas quais nosso país também é privilegiado. Fundamentalmente, estas outras práticas curativas relacionam-se à interferência da divindade maior ou da intercessão de divindades menores, mas, via de regra, por meio de um sujeito que, além de ser reconhecido pela comunidade, reconhece- 


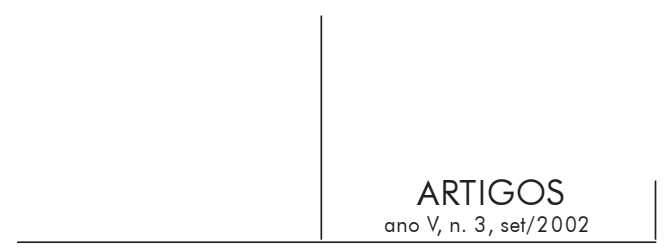

se como curador. Não é o obtido na biografia do Frei. As curas deste caracterizamse pela absoluta ausência de instrumentação pessoal de qualquer forma antiga e tradicional de poder. $\mathrm{O}$ poder de cura escorre involuntariamente de sua presença e define mais que um iniciado em artes secretas, um escolhido. Um homem que não seguiu nenhuma trilha especial, também não se dedicou ao estudo de um saber particular e nem submeteu seus espírito e corpo a sessões purificadoras. As curas foram - em qualquer sentido do termo - inconscientes. É claro que todas estas afirmações não esquecem que Frei Galvão obedeceu, sim, a formação que é exigida pela hierarquia católica para o exercício sacerdotal. O ponto é que estas exigências são propostas e obrigatórias a qualquer sujeito que pretenda desenvolver a função sacerdotal e, certamente, não um manancial de curandeiros e místicos que saem pela cidade promovendo milagres.

\section{Mais um comentário}

É o comentário final. Um tom mais perturbador, pois visa uma palavra sobre a fé e a ciência no âmbito do catolicismo, a religião da cultura ocidental por excelência.

É possível, então, supor que o Frei brasileiro representa de uma maneira clara a escrita que João Paulo II (1999) assume na carta encíclica Fides et ratio. Escreve o Santo Padre;

... na base de toda a reflexão que a Igreja leva a cabo está a consciência de ser depositária de uma mensagem que tem sua origem em Deus mesmo. O conhecimento que ela propõe ao homem não provém de sua própria especulação, ainda que fosse a mais alta, senão do fato de haver acolhido na fé a palavra de Deus... Esta é uma iniciativa totalmente gratuita que vem de Deus para alcançar a humanidade e salvá-la.

É certamente esta gratuidade do conhecimento ofertado por Deus que destaca, apesar do caráter francamente sobrenatural, as curas e os fenômenos inusuais atribuídos a Frei Galvão. O Frei, o homem que nada sabia.

É, talvez, curiosa a hipótese. Mas, apesar do necessário reparo, da necessária correção a ser feita por teólogos, filósofos, sociólogos e antropólogos, fica lançada: a melhor possibilidade do catolicismo continuar a pertencer e a influenciar a cultura ocidental, cada vez mais desencantada e cientificista, é a proclamação da gratuidade da presença divina. Derruba dois infiéis em uma pernada só. De um lado, o curandeirismo baseado no aprendizado das mais diversas práticas e em algum processo iniciático (incluídos aqui os de inspiração cristã, católica ou não); de outro lado, a razão tecnocrática-cientificista. A 


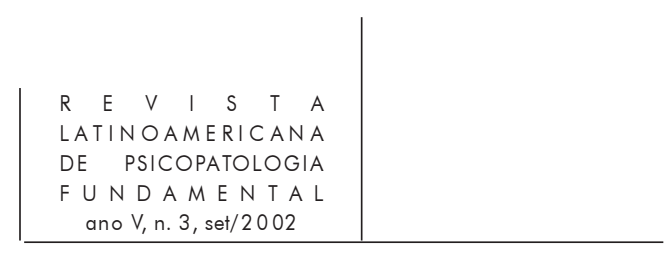

gratuidade da presença divina permite, citando João Paulo II novamente: "a peculiaridade que distingue o texto bíblico consiste na convicção que há uma profunda e inseparável unidade entre o conhecimento da razão e da fé... Assim mesmo, conhecer a fundo o mundo e os acontecimentos da história não é possível sem confessar ao mesmo tempo a fé em Deus que atua neles", dar um sentido racional à fé. Esta afirmação, esta forma de relacionar o conhecimento à fé, permite a continuidade do diálogo entre a ciência e a fé católica, nitidamente o nó que inspirou a escritura da encíclica citada. Se "os símbolos sagrados funcionam para sintetizar o ethos de um povo - o tom, o caráter e a qualidade de sua vida, seu estilo e disposições morais e estéticas - e sua visão de mundo...", como se expressa Geertz (1989), o dilema católico, o nó desta religião que advoga racionalidade, está diante da substituição de seus símbolos pelo da ciência na síntese do ethos da contemporaneidade. Proclamar que "conhecer a fundo o mundo e os acontecimentos da história" implica na fé em Deus é proclamar que qualquer conhecimento, se devidamente dirigido, se dirigido por uma ética de tom transcendente, em hipótese alguma, fere os princípios católicos. E permite que se possa pensar nas curas de Frei Galvão como efeito da presença de Deus no próprio tecido do real, sem nenhuma referência a um processo iniciático especial, produtor de um método de cura como se caracterizam as curas fora da Medicina convencional. Sem dúvida, um método em nada similar à racionalidade científica, mas, um método reprodutível.

E permite o diálogo. Permite que religião e ciência conversem. Permite que o Papa fale, ao lado de físicos e filósofos, no simpósio: Física, Filosofia e Teologia: Questões comuns para o Entendimento (Schweitzer, 1999) e aposta que um campo não desapareça sobre o outro. Ou, mais ainda, permite que a Igreja não endosse teses fundamentalistas. E tal diálogo é uma tentativa de desfazer a idéia, enraizada no pensar moderno e herdada pelo pensar contemporâneo, de "que os saberes oriundos da ciência se opõem cada vez mais à ordem profunda das certezas inscritas no sagrado" (Guitton et al, 1992). É, contrariando toda essa tradição, arriscar a aproximar a ciência da religião.

Um risco tantalizante, apesar das tentativas de filósofos e físicos nesta aproximação. A religião fala em dogmas e mistérios. A ciência em verificação e luz. A religião em moral e ética. A ciência em dinheiro e pragmatismo. Enfim, a religião fala em ritos e tradição e a ciência em ação e novos horizontes. E as novidades biológicas estão chegando. Para interferir nas noções de reprodução, vida e morte.

A quem pertence o futuro? 


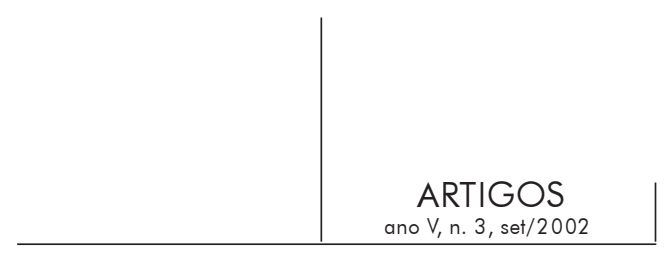

Referências

GeErtz, C. A interpretação das culturas. Rio de Janeiro; LTC Editora, 1989.

Guitton, J; Bogdanov, G; Bogdanov, I. Deus e a Ciência, em direção ao materialismo. Nova Fronteira: Rio de Janeiro, 1992.

Jỗo Paulo II. Carta Encíclica "Fides et Ratio" del sumo pontífice Juan Pablo II a los obispos de Iglesia Católica sobre las relaciones entre fe y razón. (obtida na Rede Mundial, no sítio http://www. Aciprensa.com, 1999.

KAKAR, S. Chamanes, místicos y doctores. Una investigación psicológica sobre la India y sus tradiciones para curar. Mexico D.F.: Fondo de Cultura Econômica, 1989.

Lima, Padre A.L.S. Bem aventurado Frei Galvão. São Paulo: Paulus, 1998.

Moura, C.E.M. Os Galvão de França no povoamento de Santo Antonio de Guaratinguetá. São Paulo: EDUSP, 1993.

Schweitzer, Padre Paul. Um diálogo entre ciência e fé. In: Olinto, H.K. e Schollhammer, K.E. (Orgs.). Novas epistemologias: desafios para a universidade do futuro. Rio de Janeiro: Nau Editora, 1999.

Surian, Frei Carmelo. Beato Frei Galvão. Um brasileiro na glória dos santos. Petrópolis: Vozes, 1998.

El autor toma como punto de partida la historia de Frei Galvão con el interés en preguntarse acerca del diálogo posible entre la ciencia y la religión.

Palabras llave: Frei Galvão, ciencia, religión

L'auteur, à partir de l'histoire de Frei Galvão, s'interroge sur le dialogue possible entre science et religion.

Mots clés: Frei Galvão, science, religion

Based on the life of the Brazilian priest, Friar Galvão, the author discusses the possible dialogue between science and religion.

Key words: Frei Galvão, science, religion

Versão inicial recebida em maio de 2002

Versão revisada recebida em agosto de 2002 